red light was reduced to $25 \%$, and, thereafter, sequential irradiation with red and blue light gave reversibility only up to this depressed level. However, if the red and blue exposures were separated by a dark period, $75 \%$ germination occurred.

The photoreversible effects of red and far-red light, together with the evidence of action spectra for induction and reversal, implicate phytochrome in the control of germination but the effects of blue light are incompatible with an interpretation in terms of phytochrome alone. It is postulated that an uncharacterised pigment absorbing blue light is also involved in the inductive and inhibitory responses but that not all spores contain effective levels of both pigments. Spores containing only phytochrome show characteristic phytochrome-mediated responses; spores containing only the blue light absorbing pigment show only blue light induction of germination; when both pigments are present, the phytochrome response is modified in that the effects of blue and red light are not repeatedly reversible.

\title{
Some effects of temperature on germination and protonemal growth in Asplenium ruta-muraria and $A$. trichomanes
}

\author{
J. E. Young \\ Department of Plant Science, University College, P.O. Box 78, \\ Cardiff CF1 1XL, U.K.
}

The British and European distributions of Asplenium ruta-muraria and A. trichomanes are very similar (Jalas and Suominen 1972), suggesting that the two species have similar temperature requirements for growth. Laboratory studies have shown, however, that this may not be the case. Germination of $A$. ruta-muraria spores is slower than that of $A$. trichomanes and is virtually non-existent at $15^{\circ} \mathrm{C}$ (Table 1 ).

Table 1. Percentage of spores germinating after 20 days. Spores were sown on glassfibre filter-paper discs moistened with Hoagland's culture solution at constant temperature under white fluorescent tubes with a PAR fluence rate of $40 \mu \mathrm{mol} \mathrm{m} \mathrm{m}^{-2} \mathrm{sec}^{-1}$. Each figure is the mean of 9 discs

$\begin{array}{lrrr} & 15 & 20 & 25 \\ \text { A. ruta-muraria } & 1 & 12 & 30 \\ \text { A. trichomanes } & 55 & 80 & 88\end{array}$

Detailed studies of the distribution of the two species in a small area near Malham Tarn showed that the micro-distribution of the two species differed, A. trichomanes being found in deeper crevices $(7-28 \mathrm{~cm})$ and $A$. ruta-muraria only in the shallower crevices $(1-5 \mathrm{~cm})$. A. ruta-muraria also colonises deeper crevices which are southfacing. These results suggest that $A$. ruta-muraria is colonising the warmer crevices, being excluded from the deeper ones by the high temperature requirements of spore germination. Measurement of the temperature of the base of crevices colonised by the two species confirms this conclusion, the mean temperature for $A$. ruta-muraria crevices being more than $6^{\circ} \mathrm{C}$ higher than that for $A$. trichomanes crevices. 
Laboratory studies have shown that spores of $A$. ruta-muraria imbibed at $15^{\circ} \mathrm{C}$ for periods as long as 42 days rapidly germinate when transferred to $25^{\circ} \mathrm{C}$. After 12 days, $95 \%$ had germinated. This is a higher percentage than for spores imbibed at $25^{\circ} \mathrm{C}$, suggesting that fluctuating temperatures may stimulate germination.

The restriction locally of $A$. ruta-muraria to warmer crevices, and the apparent stimulation of germination by temperature cycling, may be responsible for both the similarities of the geographical distribution of the two species despite dissimilar temperature requirements, and for the observed differences in local distribution. However, until further studies on the effects of temperature and the effects of other factors which tend to be correlated with temperature, such as relative humidity, are carried out, these conclusions can only be tentative.

Jalas, J. and Suominen, J. 1972. Atlas Flora Europea I. Pteridophyta (Psilotaceae to Azollaceae). Helsinki: Committee for Mapping the Flora of Europe.

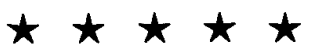

\title{
C. REPRODUCTION AND PROPAGATION
}

\author{
Preliminary studies on the breeding systems of \\ Dryopteris filix-mas (L.) Schott and D. dilatata (Hoffm) A. Gray \\ Jane Barker and A. Willmot
}

Derby Lonsdale College of Higher Education, Kedleston Road, Derby

Dense cultures of Dryopteris filix-mas and $D$. dilatata were grown on mineral agar at $20^{\circ} \mathrm{C}$ under continuous illumination. Cultures were sown either with spores from individual plants or with spores of two plants from either the same or different populations of the same species. In all cases, two types of fertile gametophytes were observed in D. filix-mas. These were: (i) large, cordate and female, and (ii) small, spatulate and male. At a later stage, many female gametophytes became hermaphrodite. $D$. dilatata produced only one fertile type. These were cordate and female and also became hermaphrodite later. From these findings, it is proposed that D. filix-mas has a bigametophytic system in which separate male and female gametophytes co-exist, at least for a while. In contrast, $D$. dilatata shows a monogametophytic system with only female gametophytes initially. Spores of each species were sown on normal medium and on medium containing previously used agar. On normal agar, results for both species were as above, but on the previously 